\title{
The Strategic Choice of Core Competitiveness in Power Generating
}

\section{Enterprises: Knowledge Management}

\author{
Qin Li, Xin Li \& Ping Zhou \\ School of Economics and Management, North China Electric Power University, Beijing 102206, China \\ E-mail: dt072350@126.com
}

\begin{abstract}
Since China's systematic reform on electric power, i.e. separation of enterprises and power grid; bidding for interconnection, increasingly keen competition has occurred in power generating industry. It is rather necessary for power generating enterprises to maintain and promote core competitiveness in order to survive the market competition. In current knowledge economy age, knowledge management is an effective choice to promote enterprise's core competitiveness. Firstly, we describe the connotation and characteristics of knowledge management and core competitiveness of power generating enterprises. Secondly, we analyze the competitive environment of power generating enterprises based on Porter's Competition Model. And then we make a SWOT analysis on implementing knowledge management to promote core competitiveness for power generating enterprises. Finally, several proposals are raised accordingly.
\end{abstract}

Keywords: Power generating enterprises, Core competitiveness, Competitive strategy, Knowledge management

Along with the embedded systematic revolution of China's electric power, electric power industry is experiencing a significant and gradual changing from industry monopoly to market competition. Future electric power market will be completely released from previous monopolistic structure of power system, but turn out to be "separation of enterprises and power grid; bidding for interconnection". As far as power generating enterprises are concerned, they have to absolutely depend on themselves to survive the market. Especially after China's entry into WTO, foreign power generating enterprises gradually participate in the industry, which has resulted in keener competition in China power market. Under this background, power generating enterprises urgently need to implement knowledge management to promote core competitiveness in order to maintain and enhance competitive advantages in power market.

\section{Analysis on Core Competitiveness and Competitive Environment of Power Generating Enterprises}

\subsection{Connotation of Core Competitiveness of Power Generating Enterprises}

The core competitiveness of power generating enterprises is formed during long period, which is unique but contained in enterprises' inner quality. It can bring enterprises with competitive advantages and achieve aggregation, combination and integration of core sources, ability and institution for sustainable survival and development in competitive power market environment.

Main characteristics of core competitiveness of power generating enterprises include the following. Firstly, value. It indicates that enterprises could be better than competitors in higher efficiency, lower cost and value creativity owing to core competitiveness. Simultaneously, core competitiveness can help to provide target customers with particular value and benefits. Secondly, differentiation. Core competitiveness has outstanding route dependence which can't be imitated by competitors or established easily. Thirdly, expansibility. Core competitiveness enables enterprises to maintain persistent competitive advantages and extend to relevant markets through innovation so as to achieve sustainable competitive advantages in the field. Fourthly, implicit characteristic. Core competitiveness is not a kind of assets, and also different from intangible assets, such as brand, patent, which can be evaluated. Its existing form is basically structural and implicit. Fifthly, non-transaction. As special asset, core competitiveness exists accompanied with enterprises, so it can't be traded at certain place as other assets do.

\subsection{Analysis on Competitive Environment of Power Generating Enterprises Based on Porter's Competition} Model

Porter's Competition Model was proposed by Michael Porter in early 1980s, which deeply influences enterprises' strategy making globally. The model consists of five competitive powers: suppliers' negotiation power, buyers' negotiation power, threats from newcomers, threats from substitutes, internal rivalry. See Figure 1. With regards to power generating enterprises, the profits are determined by the above five powers which 
indirectly influence the price, cost and investment of electric products, and finally the industrial structure. Therefore we have to realize the competitive environment and competitors when analyzing the core competitiveness of power generating enterprises.

\subsubsection{Internal Rivalry}

Competitive environment analysis focuses on internal rivalry which is the most important one of the five powers. Since China's systematic reform on electric power, i.e. separation of enterprises and power grid; bidding for interconnection, China's power generating market has become a competitive market primarily, which brings increasingly keen competition of the industry. China's power generating market is composed of four competing systems, i.e. national electric system, independent system, local system and foreign system. The national electric power system, the main force of China power generating market, includes five integrated power generating groups (China Datang Corporation, China Huaneng Group, China Huadian Corporation, China Guodian Corporation, China Power Investment Corporation) after the reform of electric system. Their total installed capacity accounts for $57 \%$ of the whole with tremendous strength and competitive capacity. The independent system (including SDIC Huajing Power Holdings co.,Ltd; China Guohua Power co.,Ltd; China Yangtze Power co.,Ltd, etc) is the secondary sector lagging behind national electricity system. Local system (Shenzhen Energy, Zhejiang Provincial Energy Group Company Ltd, Guangzhou Holdings, etc) is also an important power in the market. Foreign system (France Grid, America-Asia Grid, etc) can't deeply influence power generating market structure in certain period due to various reasons.

\subsubsection{Buyers Negotiation Power}

Buyers influence the profits of present enterprises in the industry by means of bargain and demand for better products or service quality. The main product of power generating enterprises is electricity (we don't consider heat power herein owing to its small market share). As to the particularity of electricity production, the direct customers of power generating enterprises are power grids companies, but substantially speaking, should be end-users. In regional power market, as power grids remain the natural monopoly, they become the strongest power in Porter's Competitive Model. Power grids enterprises drive price down by bidding and the methods like, which greatly hamper the survival and development of power generating enterprises. The influence of end-users on electricity power consumption represents power market demand which is relevant to national economy development, consumer income, electric products price, other energy price and so on.

\subsubsection{Suppliers Negotiating Power}

Suppliers threaten industrial competitors by raising price and lowering quality of products or services. The suppliers of power generating enterprises mainly deal with materials, fuel and equipments. $60 \%$ of the cost of firepower generating enterprises comes from fuel cost, so total cost, profits and economy benefits are considerably determined by the price of electricity and coal. Thus the negotiation power of coal mine greatly influences the competitiveness of firepower enterprises. The cost and quality of electric equipments to some extent influence the competitiveness of power generating enterprises as well.

\subsubsection{Threats from New Comers}

The threats from potential new comers lie on entry possibility, entry barriers and anticipated target of new comers. However present power industry hasn't come into perfect marketization, which leads to high barriers for entry and exit, therefore threats from potential competitors are relatively smaller than other industry. Generally speaking, new comers or potential competitors are probably coal enterprises. Because of the dependent relationship between coal and electricity, more and more coal enterprises, the main potential competitors, are willing to enter into power generating industry so that they can implement integration strategy and increase profits.

\subsubsection{Threats from Substitutes}

Compared to coal, oil, gas power products and so on, electric power products are efficient, convenient, and easy to be transported, clean and unpolluted, so they are more and more widely used in social production and human lives. Owing to all the superior characteristics of electric power, it is very difficult for other energy forms to extensively substitute electric power for industry and inhabitants using, which brings little possibility for substitutes.

\section{Knowledge Management and Core Competitiveness of Power Generating Enterprises}

\subsection{Connotation and Characteristics of Knowledge Management}

As a new thing in management field, knowledge management hasn't obtained agreement due to its complexity, 
fast renewal and different perspectives and purpose of researchers. In this paper we strongly agree this point of view: knowledge management refers to the process of organizing employees' intelligence and knowledge assets to create value. Usually value is created from these assets which are shared by employees, sectors and even other enterprises, in order to win optimal activities. The characteristics of knowledge management are as follows,

\subsubsection{Knowledge Management Has High Cost and High Returns}

Enterprises carry out knowledge management by investing plentiful manpower and material resources. The collection, transmission and disposal of knowledge need to largely apply computers and communication systems. Furthermore tangible equipments must be accompanied with corresponding technicians to work well. Evidently the implementation of knowledge management need higher cost, but achieve comparatively higher returns as well. KPMG once investigated top 100 enterprises in the world. Their benefits generated from knowledge management activities are over 200 million pound, together with many other benefits which are not evaluable by money directly.

\subsubsection{Knowledge Management is Man-oriented and Treasure Talent Persons}

In knowledge economy age, explicit knowledge may be fulfilled through a series of hardware and software, but it is relatively hard to obtain implicit knowledge of employees which is the source of competitive advantages of enterprises. Therefore enterprises should highly attach importance to utilizing talent persons, inspiring employees so as to develop their consciousness, initiative and creativity. Besides, enterprises also should construct corporation culture to create good atmosphere for communicating and sharing knowledge, and for developing implicit knowledge effectively.

\subsubsection{Knowledge Management has Various Purposes with Knowledge Share as A Core}

Enterprises implement knowledge management for their particular purposes, such as cultivating and promoting enterprises innovation ability, enhancing enterprises response ability, increasing efficiency, improving managers' insights, enhancing employees' skill and achieving value of knowledge assets. However only knowledge is shared and communicated by more people, it can be developed and innovated and benefits enterprises more. So the core purpose of knowledge management is to fulfill knowledge intensivism and share.

\subsubsection{Knowledge Management is the Game with Marketization}

Owing to the scarcity of effective knowledge which deeply influences employees' future, it is rather difficult to achieve valuable knowledge in competitive environment. Games among all powers contribute to transactions between knowledge owners and potential users. Knowledge owners expect knowledge to bring benefits for them. And knowledge is only shared substantially and put into market; its value can be most developed. So knowledge management usually turns out to be games with marketization.

\subsection{Relationship between Knowledge Management and Core Competitiveness of Power Generating Enterprises}

The formation of core competitiveness of power generating enterprises and the development of its effects are dependent on relative ability supports. Knowledge management touches many aspects of organizations, penetrating every core business of enterprise organizations. The new relationships the core business forms are more and more based on information communication and share. Correspondingly, knowledge assets based on this sort of study share become primary power for enterprises to create fortune. Knowledge is getting more and more outstanding in core competitiveness, and knowledge management is more and more significant among structural factors of core competitiveness of power generating enterprises as well. R\&D is the most intensive field of knowledge demand for enterprises, which is obtained by achieving, handling, accumulating, transmitting and sharing knowledge with knowledge management. Innovation, the final target of knowledge management, refers to create new knowledge on the basis of achieved knowledge. Response ability needs knowledge's accumulation, application and innovation so as to make use of market environment knowledge to make proper strategy and reduce risks. Application ability means transforming technology advantages into market advantages, and knowledge into products or real productivity by using production knowledge. Organizational coordination ability represents production factors (such as technology, production skills) are involved into core competitiveness by management knowledge for efficient production.

Moreover knowledge management ensure the core competitiveness of power generating enterprises can't be reproduced and imitated easily, which helps to maintain its durability and promote knowledge innovation. The effects of knowledge management on core competitiveness of power generating enterprises are shown as Figure 2 


\section{Implement Knowledge Management, and Promote Core Competitiveness of Power Generating Enterprises}

\subsection{SWOT Analysis on Knowledge Management of Power Generating Enterprises}

Power generating enterprises belong to technology-intensive industry, so the whole process of enterprises activities is accompanied with knowledge management. Currently, knowledge management is at beginning stage in power generating enterprises, and systematic theory-to-practice system hasn't been formed. Knowledge management platform need to be constructed on previous information-based condition, which results in enormous work for connecting with other matters and technical difficulties. Through SWOT analysis we can go further to make sure of the advantages and challenges for power generating enterprises to implement knowledge management.

From the above figure we can see there are strengths and opportunities for power generating enterprises to implement knowledge management. Therefore they should apply positive and systematic knowledge management strategy and enhance the integration of internal and external knowledge so as to establish a set of most suitable knowledge system to themselves. Furthermore they have to innovate constantly and keep pace with the times to maintain competitive advantages. Certainly there are also some weaknesses and challenges for power generating enterprises to implement knowledge management, which should be focused on specially. Corresponding countermeasures need to be made to make knowledge management benefit the promotion of core competitiveness for power generation enterprises.

\subsection{Proposals on Promoting Core Competitiveness of Power Generating Enterprises Based on Knowledge Management}

\subsubsection{Construct Learning Organization for Knowledge Management}

In order to adapt knowledge economy and lower carbon economy, power generating enterprises need to transform to learning organization and employees should study constantly on enterprises' production and operation. Also they have to renew knowledge systematically, strengthen knowledge communication and share, expedite knowledge transmission, pervasion and application, sufficiently mobilize employees' positivity, initiative and creativity, promote innovation and improve technology and management level. Accordingly, power generating enterprises should set up a full-time knowledge management department and appoint a chief knowledge officer (CKO) to carry out efficient knowledge management. Moreover the department and officer should be endowed with corresponding rights and duty. They will manage enterprise knowledge systematically and provide with knowledge support to production, service, sales and so on.

\subsubsection{Improve the Knowledge Base of Power Generating Enterprises}

The establishment of the knowledge base of power generating enterprises is in favor of knowledge management and application. According to Porter's Competition Model, suppliers negotiating power, buyers negotiating power and internal competitors greatly threaten core competitiveness of power generating enterprises. Therefore, the knowledge management department can establish relevant knowledge base respectively. They can establish suppliers' knowledge base to save coal source status of all coal enterprises so that they could select the optimal supplier by searching data in knowledge base when buying coal. By this means they will cut coal cost to largest extent and raise profits of the enterprises. They can establish buyers' knowledge base in which various advanced and forecast methods, previous regional power consumption and regional grid companies are saved. They are able to make scientific power marketing scheme to achieve big transaction share of planned power by forecast of power market demand and coordination with regional grid companies. They also could establish polar power generating enterprises knowledge base to save their production, environment protection and management knowledge (including electric, steam engine, boiler, fuel, ash remove, chemistry, heat labor, enterprises management mechanism, stimulation mechanism, etc). At the same time power generating enterprises should have their own knowledge bases of production, environment protection and management in order to make according management on self-situation and saved data, find out advantages and disadvantages, make improvement and extend competitive advantages per se.

\subsubsection{Improve Human Resource and Staff's Knowledge Level}

People are the subject of knowledge management. In the process of knowledge management, the accumulation, processing, using and innovation of knowledge are all accomplished by people. It is rather difficult to carry out knowledge management if people don't participate positively or sufficiently back with initiative and activity. As the provider and final user of knowledge, the improvement of staff quality necessarily drive knowledge management level up, and promote core competitiveness of power generating enterprises in the end. A variety of 
methods (such as vague systematic evaluation, gray clustering analysis, artificial intelligence) could be used to evaluate the knowledge level of employees on which they can analyze present situation and propose countermeasures to existing problems. They can get high-quality employees by recruitment, develop different kinds of training models and improve stimulation mechanism in order to promote the whole level of staff's knowledge.

\subsubsection{Construct Company Culture Environment to Benefit Knowledge Share}

Company culture is a sort of representation of core competitiveness of power generating enterprises and the basis of knowledge management. Knowledge share and innovation are the key factors of promoting core competitiveness of power generating enterprises. Owing to the complexity and polytrope of knowledge, traditional culture environment have to be reformed to achieve optimal effects of knowledge management. They should advocate knowledge creativity and share, construct open and mutual-believed cooperation environment, establish scientific achievement evaluation and stimulation mechanism, sufficiently stimulate staff's positivity of knowledge innovation, cultivate the culture environment of implicit knowledge share and scientifically manage implicit knowledge. Thus finally the culture environment of upholding innovation, dedication and helping others, which is the important premise of implementing knowledge management in power generating enterprises.

\section{Conclusion}

In order to maintain sustainable development in the market environment with increasingly keen competition, power generating enterprises must deeply learn the market environment and get unique core competitiveness. Most enterprises come into agreement that knowledge is the basis of competitive advantage. The cultivating and promotion of enterprise core competitiveness are dependent on effective knowledge management. Therefore, the market environment analysis, SWOT analysis on knowledge management and proposals in this paper to some extent contribute to promoting enterprise core competitiveness by knowledge management for power generating enterprises.

\section{References}

Ding Na. (2006). Knowledge Management and Enterprise Core Competitiveness. Management Innovation.

Drucker Peter F. (2000). Knowledge Management. U.S.A. Harvard Business School.

Jia Shuzhi. (2003). On Knowledge Management of Power Generating Enterprises. North China Electric Power University.

Porter Michael. (1988). Competition Strategy. Beijing. Sanlian Bookstore.

Yang Xiaozhou. (2005). On Knowledge Management of Firms, Knowledge Management Strategy and Core Competitiveness. Xian University.

Zhou Xing and Zhang Wentao. (1999). Cultivate Enterprise Core Competitiveness and Create Sustainable Competitive Advantages. Research on Economics and Management.

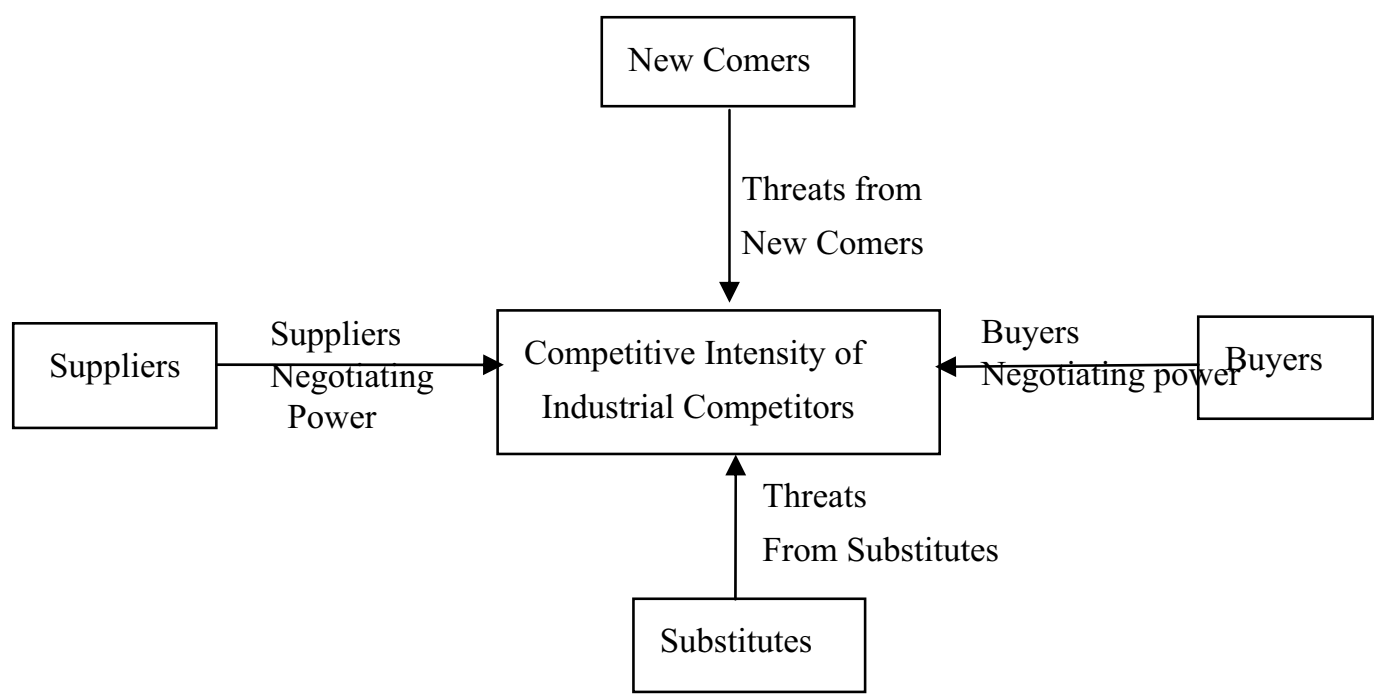

Figure 1. Porter's Competitive Model of Five Powers 


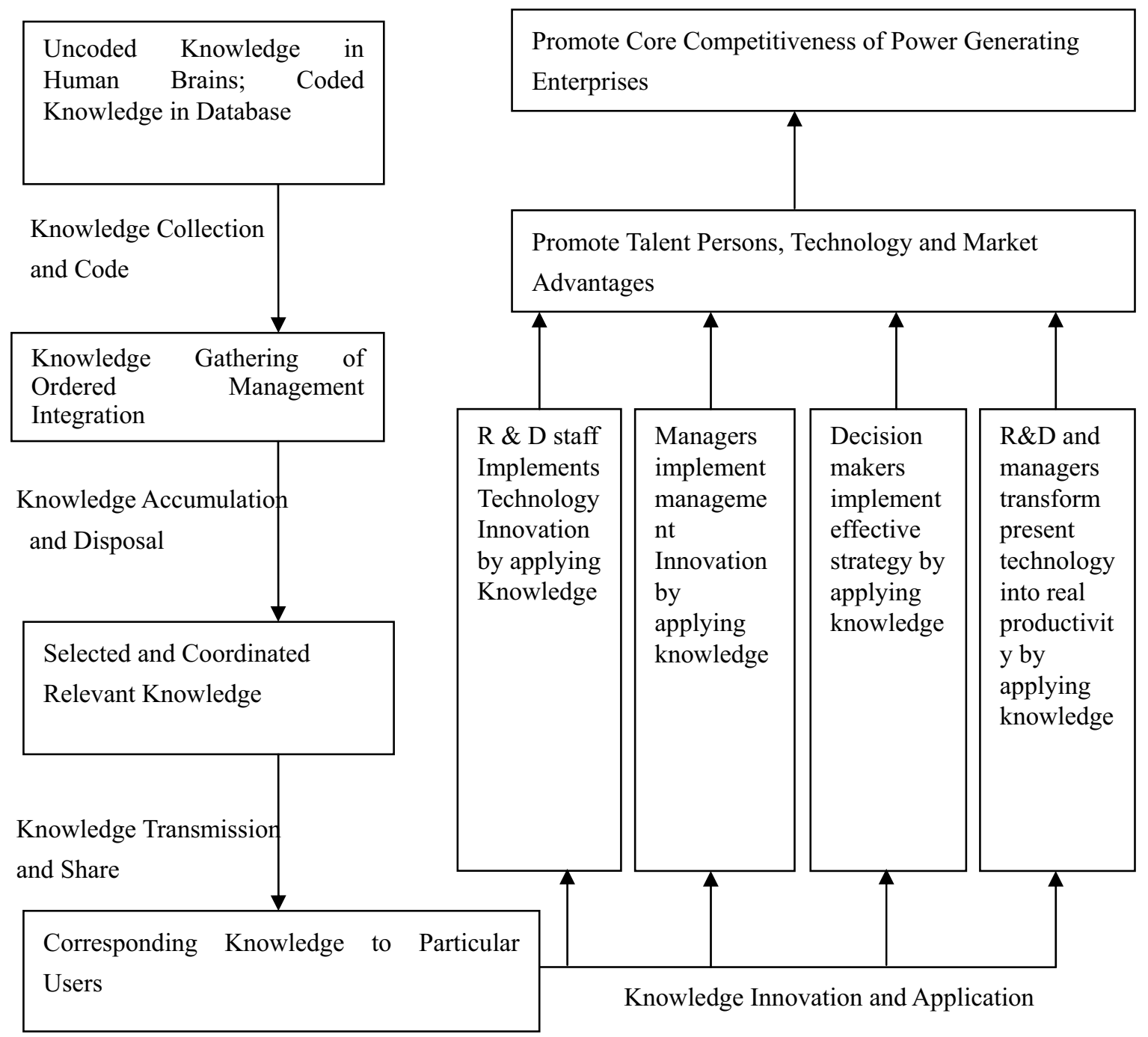

Figure 2. Processes of the Effects of Knowledge Management on Core Competitiveness of Power Generating Enterprises

\begin{tabular}{|c|c|}
\hline Strength & Opportunity \\
\hline $\begin{array}{l}\star \text { Attention of Leaders and Agreement of } \\
\text { Staff } \\
\star \text { Knowledge-and Technology-Intensive } \\
\star \text { Strong Information-Based } \\
\star \text { Strict Discipline and Emphasized Skill } \\
\text { Training }\end{array}$ & $\begin{array}{l}\star \text { Rapid Growth of Knowledge Economy Globalization } \\
\star \text { The Party and State Pay High Attention to Knowledge } \\
\text { Innovation and Upgrade of Industrial Structure } \\
\star \text { Enormous Potential of Power Demand } \\
\star \text { The Rapid Development of Information Network Technology } \\
\text { Support Transmission, Share and Innovation of Knowledge } \\
\text { Technically }\end{array}$ \\
\hline Weak & Threat \\
\hline $\begin{array}{l}\star \text { Market Environment isn’t Mature; Power } \\
\text { Supply Chain is not in Order } \\
\star \text { Passive Position in Power Market } \\
\text { Transaction } \\
\star \text { Stiff Stimulation Mechanism } \\
\star \text { Dragging Reformation Process }\end{array}$ & $\begin{array}{l}\star \text { Big Pressure for Energy Saving and Release Reduction under } \\
\text { the Background of Lower Carbon and Knowledge Economy } \\
\star \text { Working Condition of Knowledge Management is not } \\
\text { Optimistic } \\
\star \text { Staff Doubt Knowledge Share } \\
\star \text { Difficult Reproduction of Working Process } \\
\star \text { Considerable Work for Implementing Knowledge Management }\end{array}$ \\
\hline
\end{tabular}

Figure 3. SWOT Analysis on Knowledge Management in Power Generating Enterprises 